\title{
"Building Information Modeling BIM as a Development tool for the Management of Construction Projects"
}

Dr. Hayam M. Omayer: Lecturer, Architecture Department, Cairo Higher Institute for Engineering, Computer Science and Management, Cairo, Egypt.

hayamomair@gmail.com.

Eng. Nashwa S. Badawy: M.Sc. Student Department of Structural Engineering, Ain shams

University, Cairo, Egypt.

nashwa2005@outlook.com.

\begin{abstract}
:
Despite the tremendous development in the field of digital technology that produced the software and techniques influenced in the field of architecture and construction, and thus the production of architectural and urban, which is imperative that we keep up with this development, and employment and continuation of the same efficiency in all phases of the project will bridge the gap between design and implementation phase, and the most important of these techniques the use of Building Information Modeling (BIM), it is a Database, Not just 3D Drawings, it refers to a digital collection of software applications designed to facilitate coordination and project collaboration, BIM has the potential to provide more efficient operation, not only as part of design and construction but also in operations and maintenance. Accuracy is another main reason. BIM appears to offer greater accuracy than what our current practices produce. This paper aims to determine the benefits of integrating BIM technique in project management and recognize the role they play in The construction industry and practical feasibility of it compared to the previous systems, the practical study depended on two parts, the first by carrying out structured questionnaire survey from construction industry' experts. The second is a case study. The paper is concluded with some important results. It seeks to show that the BIM systems improve communication, collaboration, higher-quality project decision making, and more comprehensive planning and scheduling. In the end, we should see better quality, plus increases in productivity and profitability.
\end{abstract}

Keywords: BIM, Management, Construction project.

\section{Introduction}

BIM is a representation of the information model, it is not like AutoCAD technique that can barely draw everything is done but uses a specialist in all phases of the project from design and implementation until the operation phase of the building. BIM is the current expression of digital innovation in the field of building and construction. The project team was able to be clear, fast and more accurate trading information than traditional methods, which is reflected positively on the progress of all phases of the project and provide a supportive model for the process of decision-making and thus avoid problems and minimize losses and save cost. It gives a clear picture of the project to encourage departments to participate and avoid any conflicts, allowing early to find solutions before starting the implementation of the project. This paper aims to determine the benefits of integrating BIM technique in project management and recognize the role they play in The construction industry and practical feasibility of it compared to the previous systems, the practical study depended on two parts, the first by carrying out structured questionnaire survey from construction industry' experts. The second is a case study. The paper is concluded with some important results.

\section{Research Objectives}

The main problem which faces the construction projects is not about the building or the management, it is about information. The paper seeks to study the effect of implementing Building Information Modeling BIM on the mitigation of construction project management during all phases of the project. The study was 
depended on a designed survey via emails and face to face interviews. This survey represents two parties. The first one is about implementing BIM in the construction industry. The second one investigates BIM as a management tool (Implementation, Cost of applying, benefits, and effects on project risks). Besides, one case study was investigated with and Without BIM.

\section{Literature Review}

This paper reviews a series of studies that dealt with in context the benefits of using BIM in construction projects, (Rana Mamdouh Hosney, 2016) characterized Conclusions concerned with benefits of using BIM in construction industry These benefits include, Increases safety management of the project, Ensures cost and time control for the project, Improves risk management, Facilitates value engineering process and application, Introduces clash detection process for the project activities to check the coordination between project systems (civil, architectural, electromechanical, HVAC, telecommunication, firefighting systems, and others), Improves and accelerates cost estimation for the project and makes it more accurate, Helps in resource allocation and making storage plan (procurement plan) for projects, Provides visual representation of project model, Helps in energy saving, understanding project different plans (execution plan, logistic plan, safety plan, etc.), applying sustainability features for the project, (William Michael Duke, 2013) examined that BIM benefits usually result in decreased cost, decreased time, increased quality, or a combination of the three. The main benefit BIM offers any project is increased collaboration. By using BIM, project teams can more effectively communicate with one another and create innovative and optimized solutions. While creativity is encouraged in construction, (Kiavash Parvan, 2012) proposed a model has the potentials to include other project factors such as project size, construction type. $\mathrm{He}$ examined that among all parties who are involved in the design process; architects are exploiting BIM more than the others. The MEP design also is shifting fully to BIM. (Hammad,
Rishi, and Yahaya, 2012) researched how to mitigating construction project risk using Building Information Modeling (BIM). Mitigating risk in construction projects has been considered as an important attempt to achieve the project's objective in terms of time, cost, quality, safety, and sustainability. (Darrell Ernest Thompson, 2012) researched quality with $\mathrm{BIM}$ in Texas. The findings regarding the Quality BIM revealed $40 \%$ were not engaging in the use of the Quality BIM at all and 60\% were suggesting the use or familiarity of the Quality BIM ranging from some uselawareness moderate uselawareness, and extreme uselawareness. However, those truly engaged in utilizing Quality BIM accounted for $22.1 \%$ while the remaining $87.9 \%$ were not fully engaged in the use of Quality BIM. (Kamal Shawky, 2012) always say, two software's are essential and are the most important twodimension software in the world, and it operates its style and technology. The Revit is the most important software in the modern era that uses BIM technology, so the user should have sufficient knowledge of both software, beginner AutoCAD and advanced Revit. Therefore, I do not encourage leaving AutoCAD completely and move on to Revit, but instead develop our knowledge, experience, and proficiency by learning Revit along with AutoCAD, when the world dispenses AutoCAD completely, at that time I will tell you to forget AutoCAD.

\section{Research Methodology}

The reason for this paper is to show the returned benefits and constraints of using BIM in the construction industry. The methodology used for this research approach depends on a detailed literature review; a field survey. The questionnaire covers how to deal with the implementation of building information modeling BIM in construction projects with viewing charts to view the percentage of implementation of BIM in Egypt. Then, the case study to cover the role of Building Information Modeling BIM in dealing with the project management and provide 4-Dimensions and 5Dimensions models to view the difference in 
time and cost with and without using BIM.at the end the paper discusses the Conclusion.

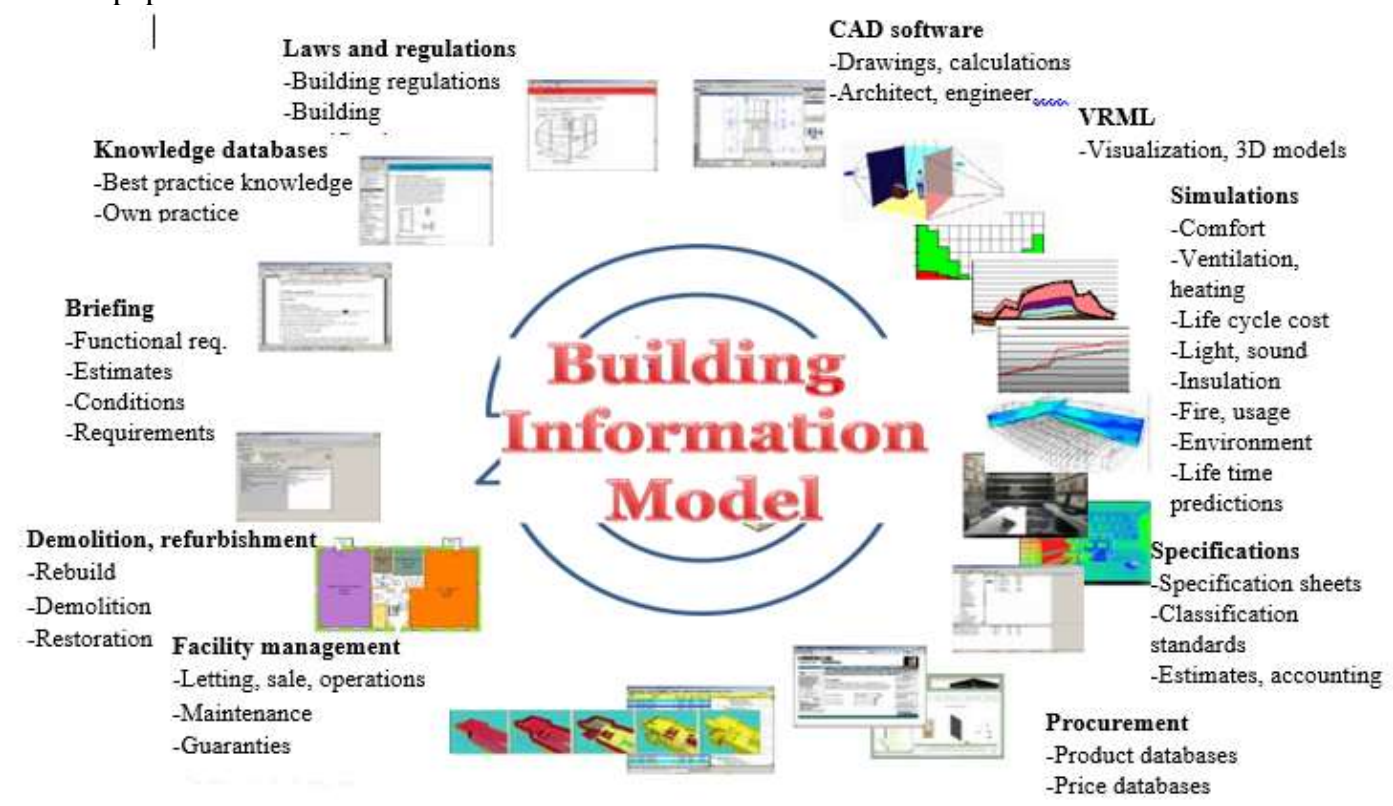

fig. 1 Large scale BIM lifecycle information view.

\section{Questionnaire Survey}

\subsection{Survey Population Selection and Sample Size Calculation}

The sample is of a limited extent that goes about as a representation of the absolute focus on the population. The focus of this research is to examine how incorporated organizations' classes $1 \& 2$ as indicated by the Egyptian Federation of Construction and Building Contractors consider the use of BIM.

Equation 1 - Cochran Formula

$\mathrm{N}=\left(\mathrm{P} * \mathrm{Q} * \mathrm{Z}^{\wedge} 2\right) / \mathrm{C}^{\wedge} 2$

Where: $\mathrm{N}=$ the first estimate of sample size, $\mathrm{Z}=1.96$ for $95 \%$ confidence level, $\mathrm{P}=0.5 \%$ selecting a choice, $\mathrm{C}=0.09$ margin of error $9 \%$, $\mathrm{Q}=1-\mathrm{p}$

Equation $2-$ Solv in's Formula

$\mathrm{N} 0=\mathrm{N} /\left(\left(1+\mathrm{N}\left(\mathrm{C}^{\wedge} 2\right)\right)\right.$

Where: $\mathrm{N}=$ Total population

According to The Egyptian Federation of Construction and Building Contractors which located in Nasr City in Cairo. The number of building contractor category 1 is 218 contractor companies, the number of building contractor category 2 is 187 contractor companies and the number of building contractor category 3 is 286 contractor companies.

A survey is developed for category 1 and category 2 from the building contractors so,

$\mathrm{N}=218+187=405$ contractor companies.

$\mathrm{NO}=405 /((1+405(0.09) \wedge 2))=94.615$ contractor companies.

Take sample size of 95 contractor companies.

100 companies are selected as a sample.

There were 130 copies of questionnaires distributed to the potential respondents in the organizations within the construction industry. Different ways used to distribute questionnaires: (Delivered for the number of companies directly through a meeting with their engineersDelivered to different companies by

email. Questionnaire was created in a survey website to be easier to reach different companies-a copy of the survey and its link was 
put in public media outlets like groups for BIM engineers at different pages to collect random responses of the 130 questionnaires, 100 copies (70 percent) returned and there were 86 copies (86 percent) from the contractor and 14 copies (14 percent) from consultants. The collected questionnaires were reviewed and analyzed by the SPSS (Statistical Package for Social Sciences) program.

Cronbach's $\alpha$ coefficient. This technique is utilized to gauge the unwavering quality of the poll between each segment and the mean of the considerable number of classifications of the survey. The ordinary scope of Cronbach's $\alpha$ coefficient is somewhere in the range of 0.0 and +1.0 , and the higher qualities mirror a higher level of interior consistency. The general dependability of all gatherings approaches 0.897 . This range is viewed as high, and more noteworthy than 0.70 . Along these lines, the unwavering quality of the survey is guaranteed.

\begin{tabular}{ll}
$\begin{array}{l}\text { Reliability Statistics } \\
\text { Cronbach's Alpha }\end{array}$ & N of Items \\
\hline .897 & 100 \\
\hline
\end{tabular}

\subsection{Results and Data Analysis}

\subsubsection{Does Your Company Currently Implement BIM?}

As seen Fig. 2, 75\% of the total respondents did not implement BIM in their companies, 23\% of the total respondents implemented BIM in their companies and $2 \%$ of the total respondents will implement BIM soon. That means that $77 \%$ of all respondents did not use BIM yet.

The companies which apply BIM in Egypt are (Orascom Construction-IBIMS(Integrated BIM Services)-CCC Consolidated Contractors International Company-Dar Al-HandasahTalent Engineering Company Egypt-SIAC Construction-EHAF Consulting EngineersHassan Allam Holding-The Arab Contractors(Alex branch)-Rowed Modern Engineering-REDCON Construction-Dorsch International Consultant-Arabian International Company AIC-Gama Construction-DMG Dar Al Mimar Group-Zuhair Fayez Partnership-AlMarasem International For Development-
Khatib\&Alami-UECC United Engineering Construction Company-Saudi Diyar ConsultingECG Engineering Consulting Group-PetrojetENPI).

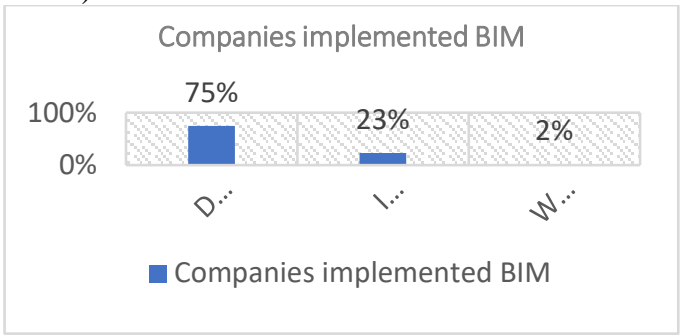

Fig. 2- Implementation of BIM

\subsubsection{The effect of the implementation of BIM on preparation of tender and contract documents:}

As seen in Fig. 3, 12\% of the total respondents say that the implementation of BIM had medium effect on preparation of tender and contract documents which represent 52\% from who implemented BIM, $8 \%$ of the total respondents say that the implementation of BIM had a low effect on preparation of tender and contract documents which represent $35 \%$ from who implemented BIM and only $3 \%$ of the total respondents say that the implementation of BIM had a high effect on preparation of tender and contract documents which represent $13 \%$ from who implemented BIM. That means that more than $50 \%$ of the companies which implemented BIM suggested that the effect of BIM system on the preparation of tender and contract documents is medium and the remaining of those who implemented BIM suggest BIM had no effect on the preparation of tender and contract documents.

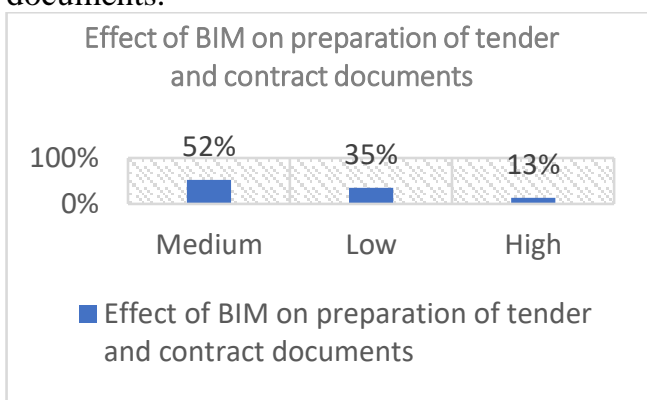

Fig. 3- BIM and preparation of tender and contract documents. 


\subsubsection{The effect of the implementation of BIM on the cost of the lifecycle:}

As seen in Fig. 4, 14\% of the total respondents said that the implementation of BIM had a medium effect on the project lifecycle costing which represents $60 \%$ from who implemented BIM and $9 \%$ of the total respondents said that the implementation of BIM had a high effect on the project lifecycle costing which represent $40 \%$ from who implemented BIM.

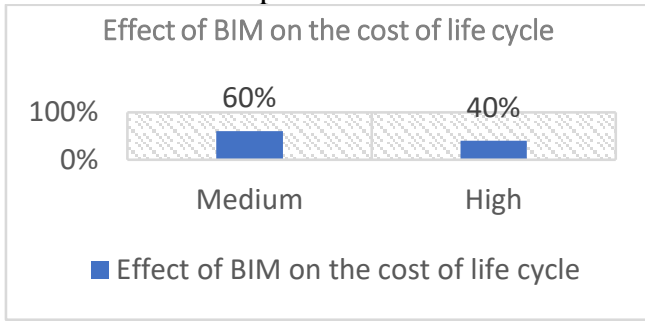

Fig. 4- BIM and project lifecycle costing

\subsubsection{The effect of the implementation of BIM on identifying and developing responses to risks:}

As seen in Fig. 5, $12 \%$ of the total respondents said that the implementation of BIM had a high effect on identifying and developing responses to risks which represent $52 \%$ from who implemented BIM and $11 \%$ of the total respondents said that the implementation of BIM had a medium effect on identifying and developing responses to risks which represent $48 \%$ from who implemented BIM. That means that approximately $50 \%$ of the companies which implemented BIM suggested that the effect of the BIM system on identifying and developing responses to risks is high.

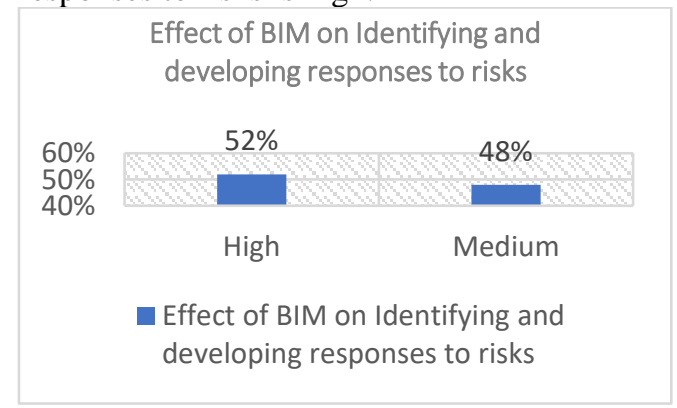

Fig. 5- BIM and identifying and developing responses to risks

\subsubsection{The effect of the implementation of BIM on analyzing proposed outcomes:}

As seen in Fig.6, 13\% of the total respondents said that the implementation of BIM had a medium effect on analyzing proposed outcomes which represent $57 \%$ from who implemented BIM and $10 \%$ of the total respondents said that the implementation of BIM had a high effect on analyzing proposed outcomes which represent $43 \%$ from who implemented BIM.

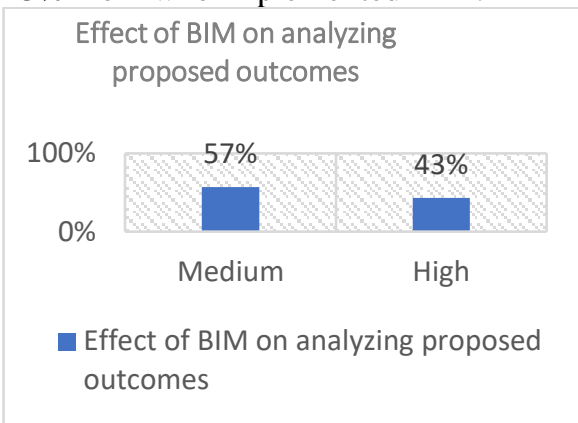

Fig. 6- BIM and analyzing proposed outcomes

\subsubsection{The effect of the implementation of BIM on valuing completed work and arranging payments:}

As seen in Fig. 7, 12\% of the total respondents said that the implementation of BIM had a high effect on valuing completed work and arranging payments which represent $52 \%$ from who implemented BIM and $11 \%$ of the total respondents said that the implementation of BIM had a medium effect on valuing completed work and arranging payments which represent $48 \%$ from who implemented BIM.

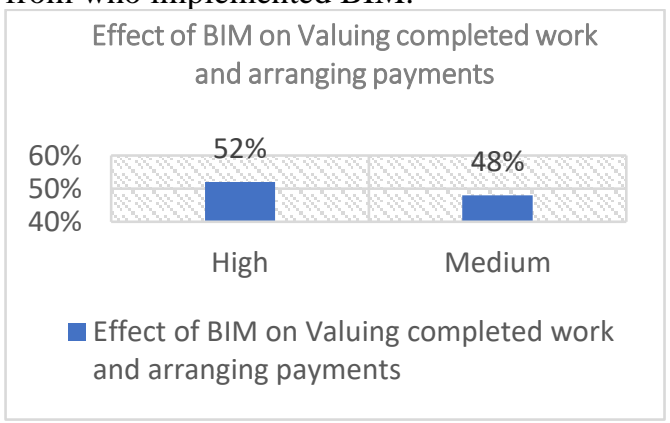


Fig. 7- BIM and valuing completed work and arranging payments

\subsubsection{The effect of the implementation of BIM on clash detection during the design phase:}

As seen in Fig. 8, 18\% of the total respondents said that the implementation of BIM had high effect on clash detection during the design phase which represents $78 \%$ from who implemented BIM and $5 \%$ of the total respondents said that the implementation of BIM had a medium effect on clash detection during the design phase which represents $22 \%$ from who implemented BIM. That means that approximately $78 \%$ of the companies which implemented BIM suggested that the effect of the BIM system on clash detection during the design phase is high.

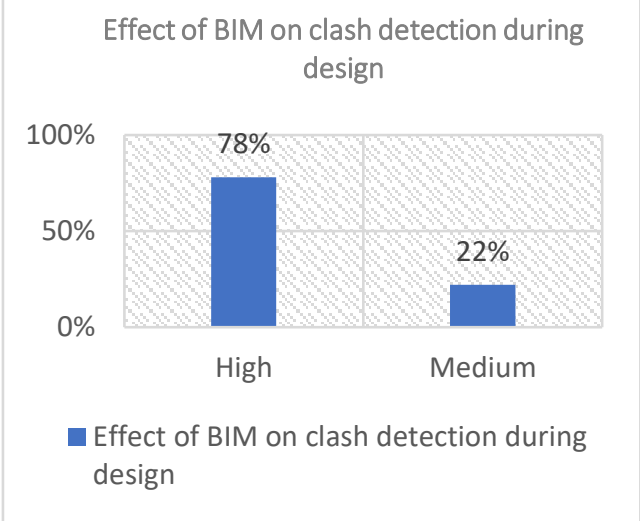

Fig. 8- BIM and clash detection during the design phase

\subsubsection{Projects implemented BIM in them:}

As seen in Fig. 9, 13\% of the total respondents implemented from (1 to 5) projects with BIM which represent $57 \%$ from who implemented $\mathrm{BIM}, 8 \%$ of the total respondents implemented from (6 to 10) projects with BIM which represent $35 \%$ from who implemented BIM and $2 \%$ of the total respondents implemented from (11 to 15 ) projects with BIM which represent $8 \%$ from who implemented BIM.

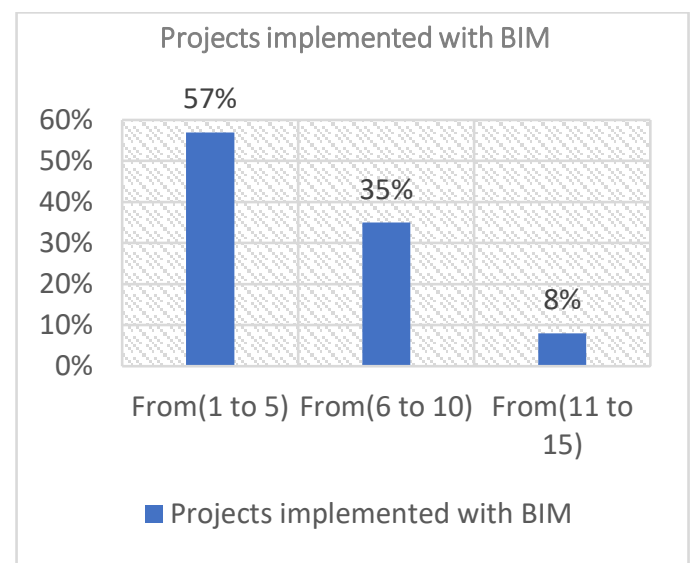

Fig. 9- Projects you implemented BIM

\section{Model Verification}

This paper included one case study explained in detail. The following case study displays the difference between executed the project with the traditional method and with applying BIM technology on it and showed the effect of applying BIM to controlling risk in construction projects especially in the design phase. Case study el-sheik Zaid Al Nahyan Nasr road Hospital.

A case study is presented in a hospital located in Egypt is considered for this purpose. The hospital has a capacity of 150 beds with a total area of 27500 square meters. The main hospital building is a basement, a ground floor, and five floors, with a floor area of 2000 square meters, in addition to the service buildings. It is a cylinder store, the ground reservoir, the pump room, Boilers, medical gases, fences, and

general site coordination. The hospital cost approximately $=118,000,000$ EGP.

\subsection{D Model from AutoCAD} (Traditional Way)

In the traditional way, the plans showed by AutoCAD programs it is a 2-dimensional model 


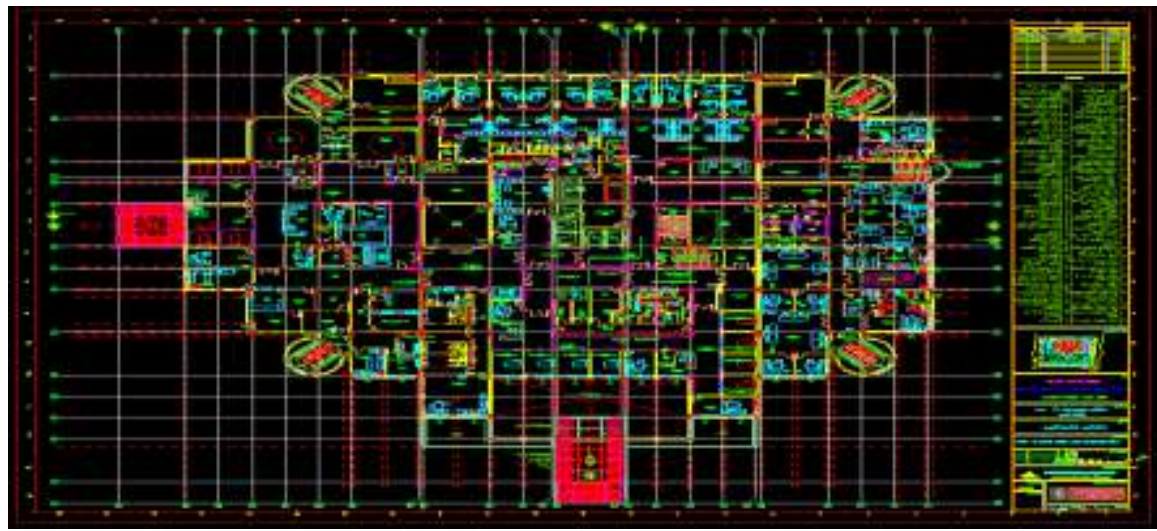

Fig. 10- Zayed hospital Arch. First - floor slab

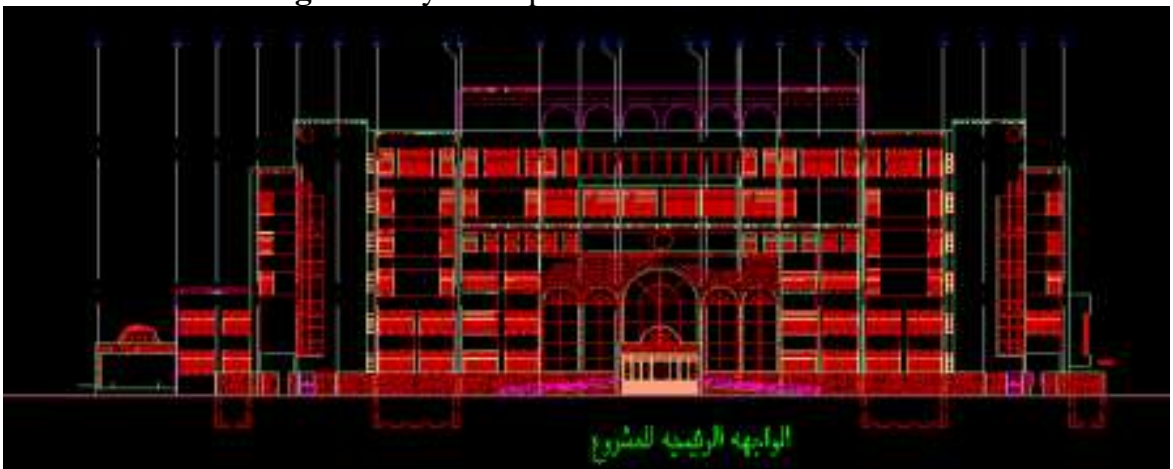

Fig. 11- El Sheikh Zayed 2-Dimensional model elevation from AutoCad

3D model from Revit (BIM)

In BIM technology the plans showed by Revit program in 3-D models. It's very clear and easy to be clear for all the stakeholders.

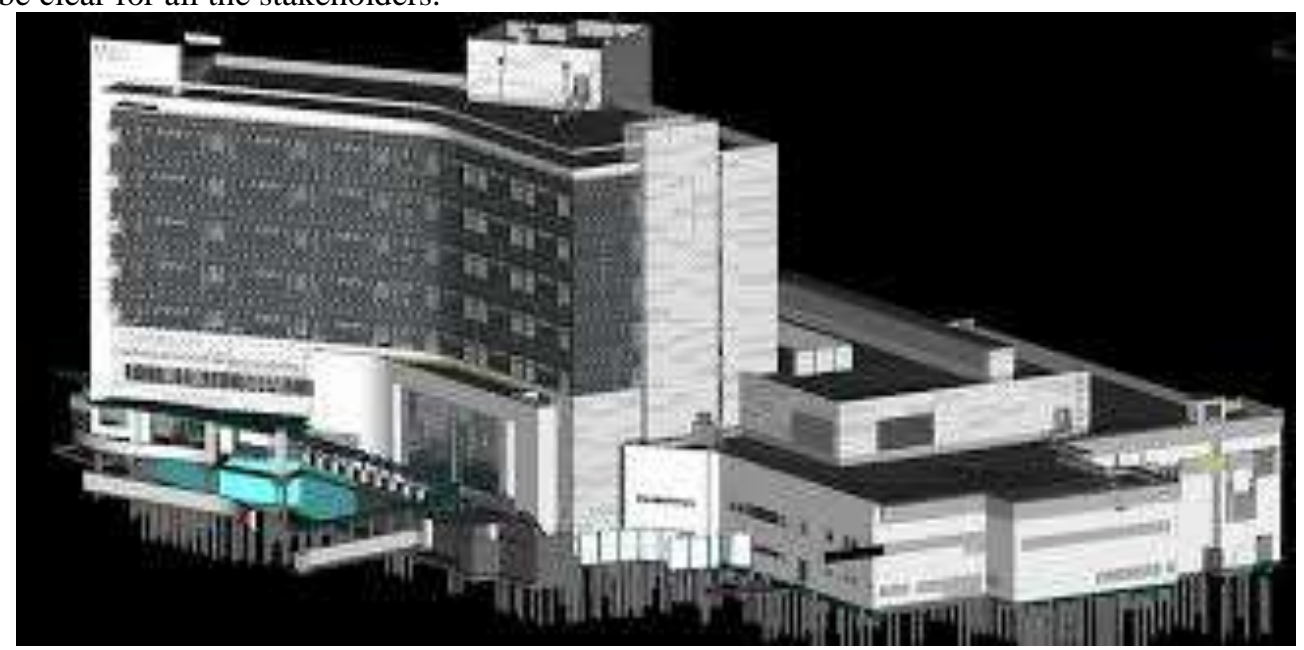

Fig. 12- El Sheikh Zayed Hospital 3D models from Revit

From 3D model extract details for the construction component shown in figures below. 


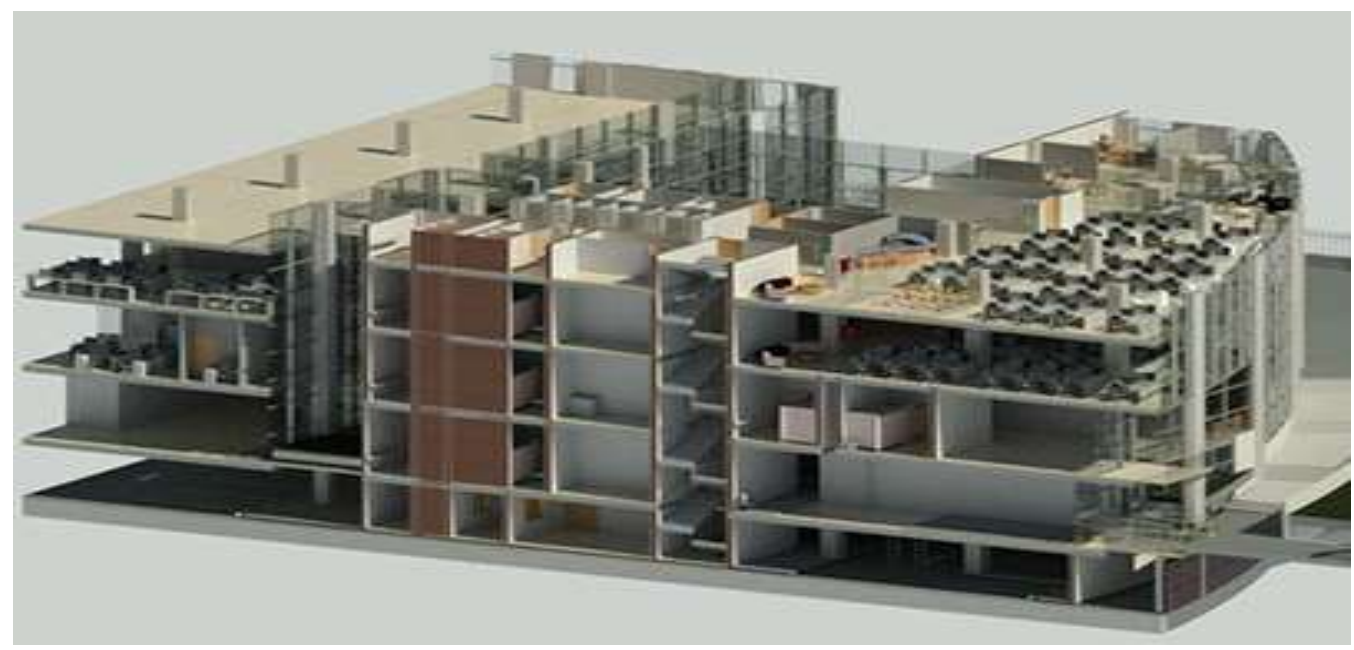

Fig. 13- El Sheikh Zayed Hospital 3D section from Revit

From the received 3D model, the contractor starts to extract some needed data about each element of the project. Such as, bill of quantities, schedules and shop drawings data will be available in the model and can be extracted quickly.so, these data are collected in a table extracted from the BIM model.

\subsection{Clash Zone at Design PhaseThe 3D model most benefit is Clash Detection such as:}

- Eliminate defects and conflicts during design and modeling.

- Eliminate defects and conflicts during the overlap between systems of the project like (civil, architect, electrical, mechanical, etc.).

- Reduce cost and time consumed in correcting the defects appeared in the construction phase and instead correct it early in the design phase.

- Increase the overall productivity of the project.

- Have a trusted one model for the project to transfer it to the parties of the project, (Bloomberg, (2012)).

- Fire Protection Systems vs. Electronics Systems, (Bloomberg, (2012), Campbell, D.A., (2007).
- Different sorts of conflict may include the booking of contractual workers, the conveyance of hardware and materials, and the general course of events clashes. These are frequently alluded to as 'Work process or 4D conflicts'.

\subsubsection{Clash zone and Clash detection:}

According to the poor communications between the stakeholders, there are a lot of clashes happened between their works like the clash shown in figure 14,15 and figure 16 showed how to resolve it.

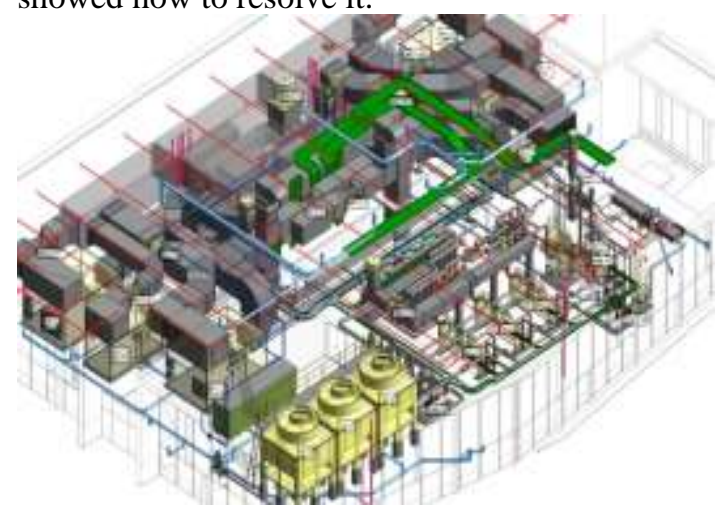

Fig. 14- Hospital BIM modeling-MEP 


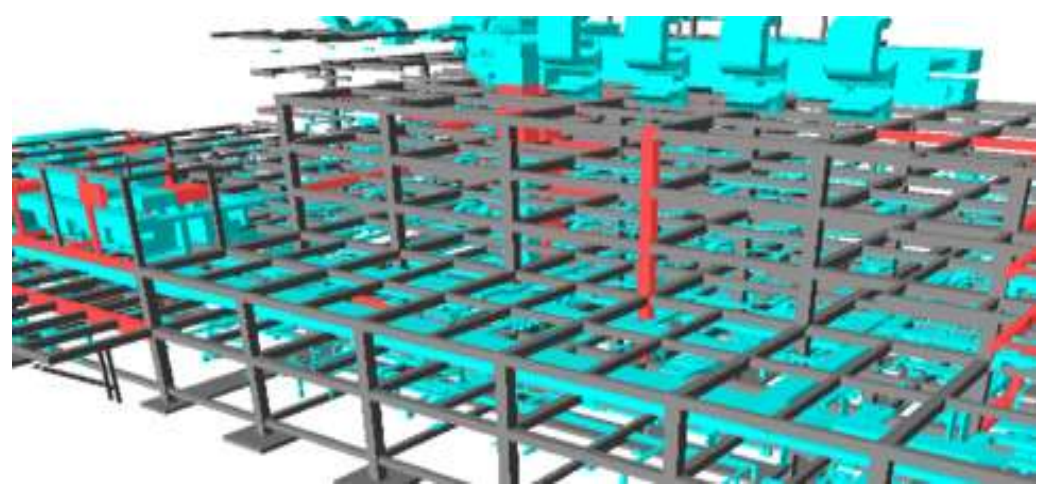

Fig. 15-3D model for the hospital MEP system

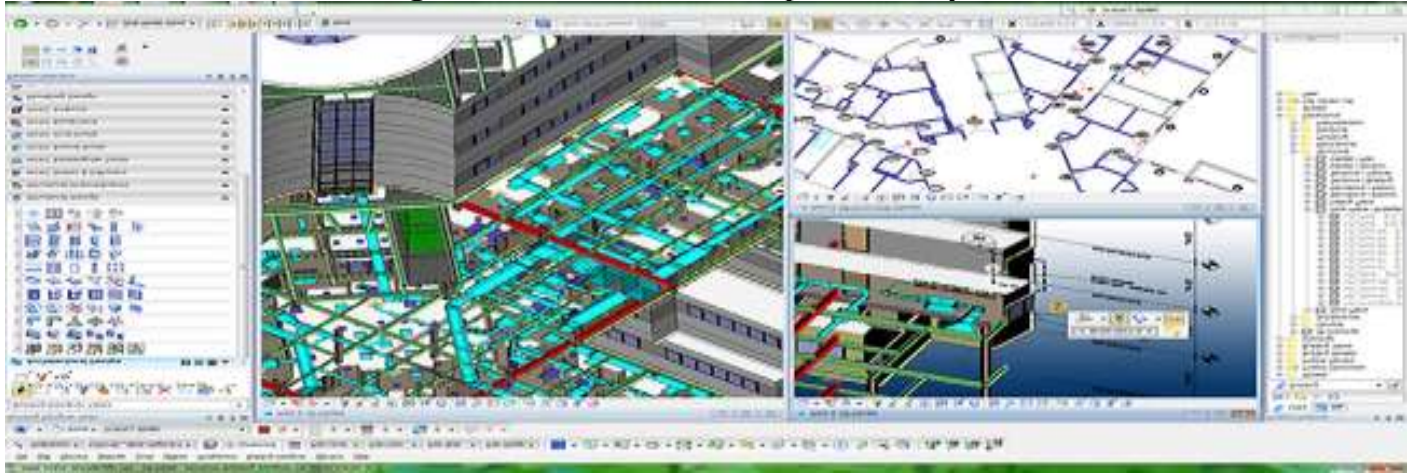

Fig. 16- Zayed hospital MEP modeling plan

\subsubsection{Clash detection steps:}

- Import 3D Revit files into Naviswork.

- Press the Clash Detective tool to test conflict performing in Naviswork programming

- Snap-on the 'Select' tab that is situated inside a conflict analyst device in Naviswork programming as observed in fig. 17 .

- Autodesk Naviswork consequently gives status to each conflict for sometimes later. So, after that the Clash Detective apparatus that continues refreshing the status of the conflicts after they are distinguished and is recorded inside the Results tab as observed in fig.18.

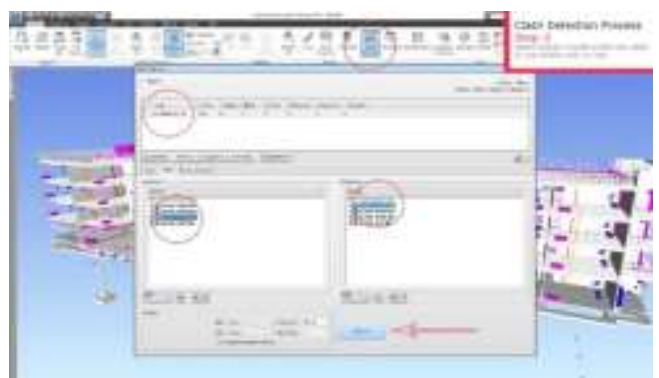

Fig.17. Clash report generated by Naviswork

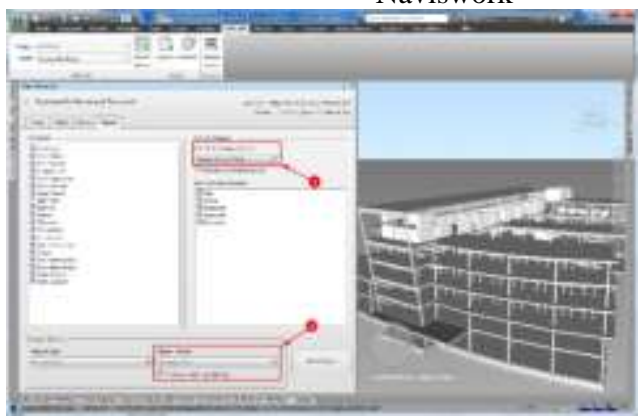

Fig.18.Clash Detective showing the results 


\subsection{D BIM model with Navies work program (Time schedule)}

The 4D model is the combination of the 3D model and the schedule of the project.

Achieved benefits from combining of 3D model and time in El Sheikh Zayed Hospital Project:

- Coordinated timelines of construction operation between all systems.

- What-If-Scenarios/hosting of alternatives.

- Availability of materials of each activity before the start date.
Developing a time schedule model with the Navies work program by connecting with the Revit model that model is more accurate and solves a lot of problems.

The following images show the steps of some weeks of the project in details and showing the overlap of the works that happen at the same time in the different zone in the project. Daily activities taking place during the project is reflected as shown below with previews of works done in the project.

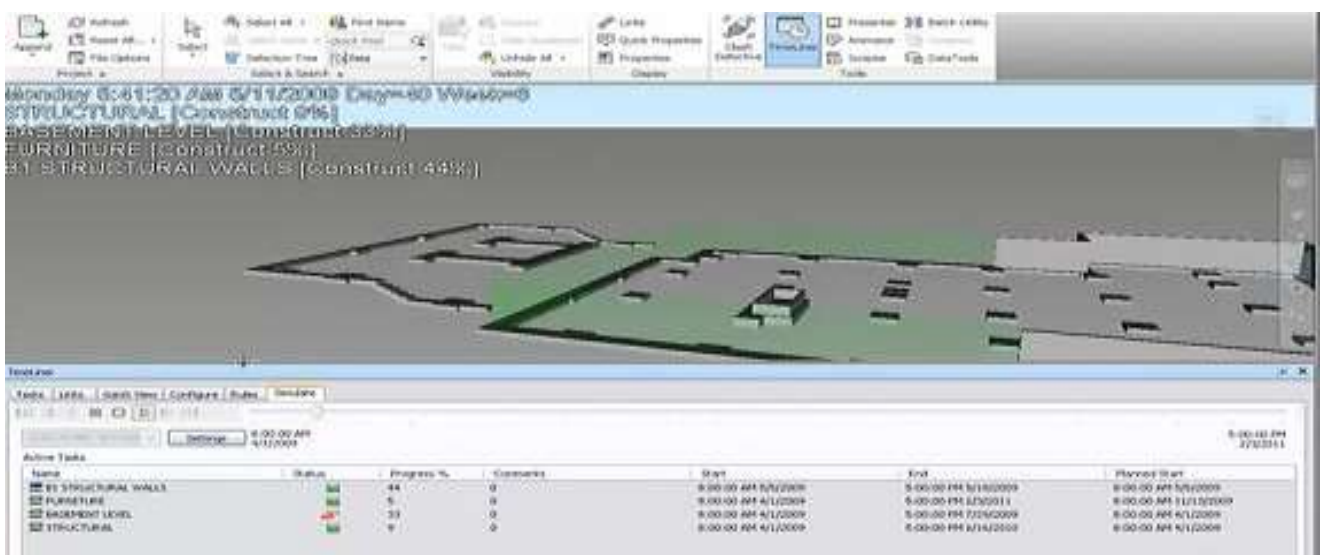

Fig.19. Day 30 in week $8 \rightarrow$.

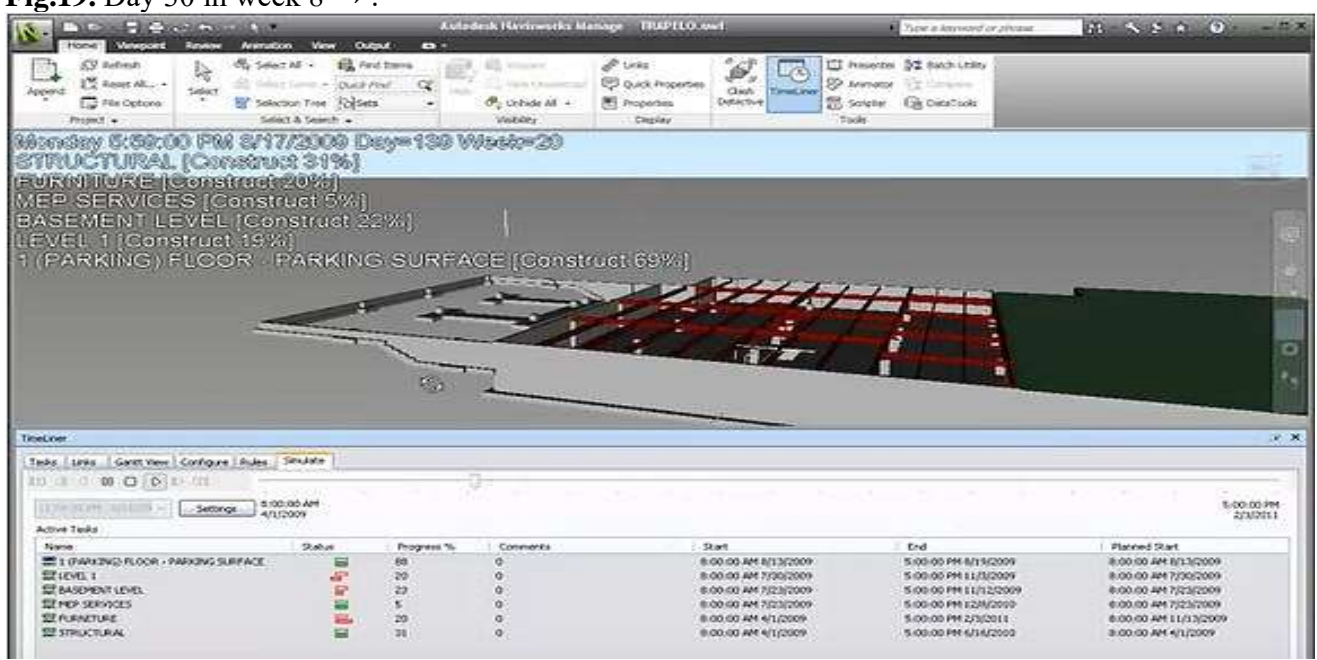

Fig.20. Day 139 in week $20 \rightarrow$ excavation (38\% stage 2 \& 2\% stage 4 ).

$\rightarrow$ construction $(88 \%$ Columns standalone $\mathrm{Z1})$.

$\rightarrow$ construction ( $90 \%$ first slab type $\mathrm{z}$ zone 1$) \&(41 \%$ second slab)

$\rightarrow$ construction (82\% first wall type z zone 1$) \&(55 \%$ roof slab 


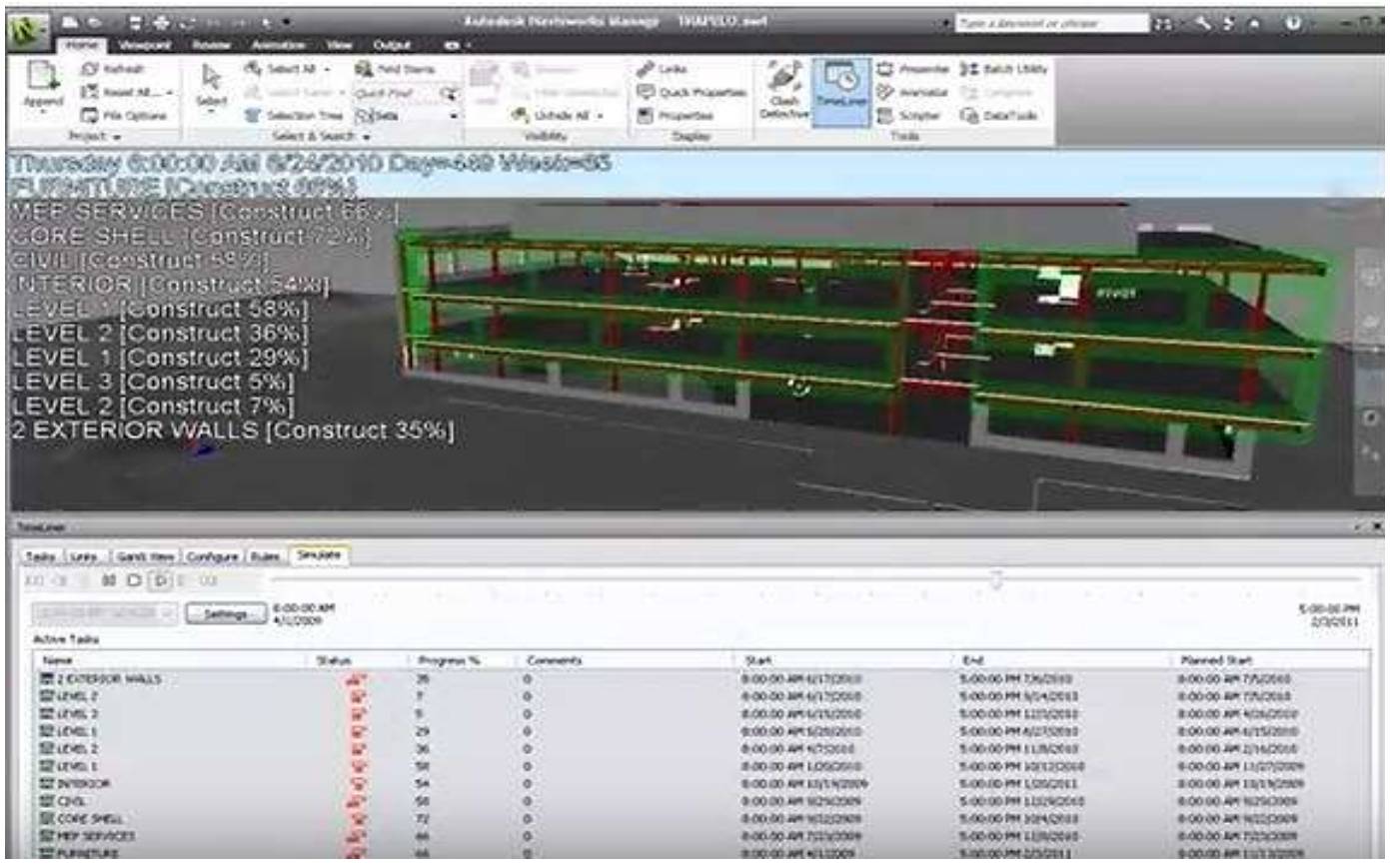

Fig.21. Day 689 in week $55 \rightarrow$ excavation (38\% stage $2 \& 2 \%$ stage 4$)$.

$\rightarrow$ construction $(88 \%$ Columns standalone $\mathrm{Z1}$ ).

$\rightarrow$ construction ( $90 \%$ first slab type z zone 1$) \&(41 \%$ second slab)

$\rightarrow$ construction $(82 \%$ first wall type z zone 1$) \&(55 \%$ roof slab

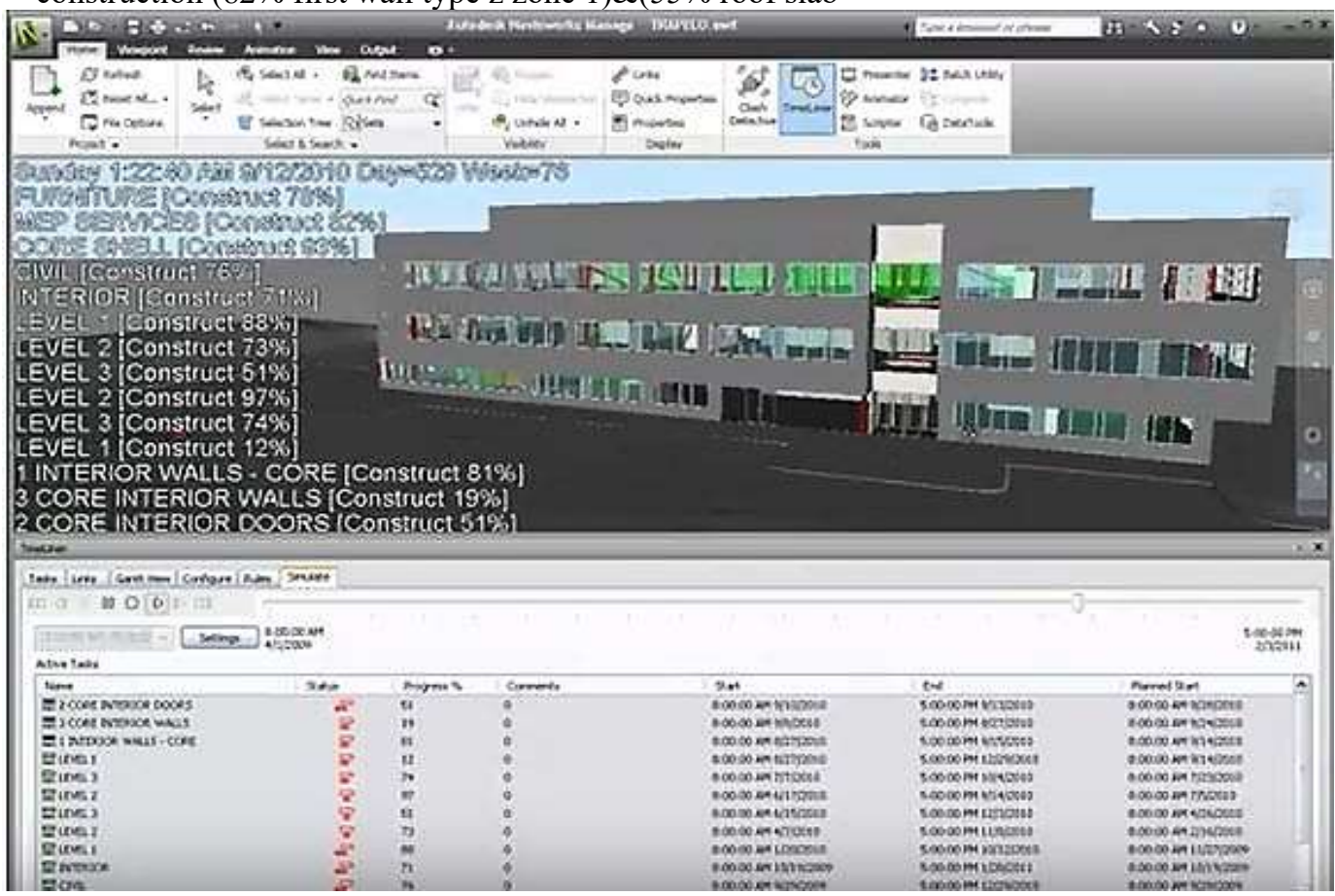

Fig.22. Day 539 in week $78 \rightarrow$ construction $(100 \%)$ 
The BIM 4-dimensional model shows every day in the project life cycle and the percentage done in every activity every day.

The 4D model shows that the construction of all units without finishing took 114 weeks approximately 2 years and the finishing for all types took 21 weeks

\subsection{Bill of Quantities (BOQ)}

The traditional method calculated of the Bill of Quantities (BOQ) shown in Table 1 and defining alternatives on the application and exported quantities from Revit files.

\begin{tabular}{|c|c|c|c|c|c|}
\hline & 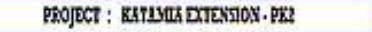 & & & & \\
\hline & 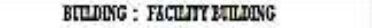 & & & & \\
\hline $\begin{array}{ll}\mathrm{mal} \\
\mathrm{H}\end{array}$ & iescrentos & thin & QTi. & $23 \pi$ & IX0037 \\
\hline 1 & 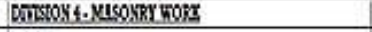 & & & & \\
\hline & 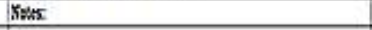 & & & & \\
\hline & 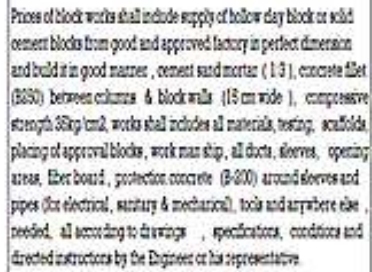 & & & & \\
\hline 11 & 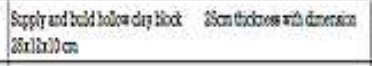 & & & & \\
\hline III & Futsurat boot & y3 & 30 & & \\
\hline III & FravedSse & H & 45 & & \\
\hline $11: 2$ & furfuspor & 33 & 38 & & \\
\hline 1.14 & fastoudinest & Y3 & औै। & & \\
\hline 115 & Funtasebud & $y_{3}$ & sit & & \\
\hline
\end{tabular}

Table.1.Case study BOQ by traditional method
Activities classifications

$\begin{array}{lll}\text { Duration Index } & \text { (DI) }= & \text { Actual } \\ \text { Duration/Original Planned Duration } & \end{array}$

Duration Index (DI) for the project = Actual Duration/Original Planned Duration = $1890 / 1095=1.726$

Cost Impact $\%=($ New cost-Previous cost)/Previous cost

New cost $=(242,000,000+118,000,000)$ $=360,000,000$ EG.P

Cost Impact $\%=(\quad(360,000,000-$ $242,000,000) / 242,000,000)) * 100=48.76 \%$

According to the contract: The amount of liquidated damages for delay in completion of sections is calculated as the following:

1- (EGP 24,200 per day shall be applied for each day of delay up to ten days).

2- (EGP 36,300 per day shall be applied for each day of delay after ten days up to 20 days).

3- (EGP 48,400 per day shall be applied for each day of delay after 20 days).

4- Liquidated damages not to exceed $10 \%$ of the contract price.

The main cause of delay for AL Nahyan Hospital is the Revolution in Egypt on 25 January 2011 and this problem no one can expect or avoid it and because of that, the Cost Impact is very high and not acceptable. The total delayed date is 795 day but only 90 days can be affected by implemented BIM technology.

\section{Risk analysis summary report}

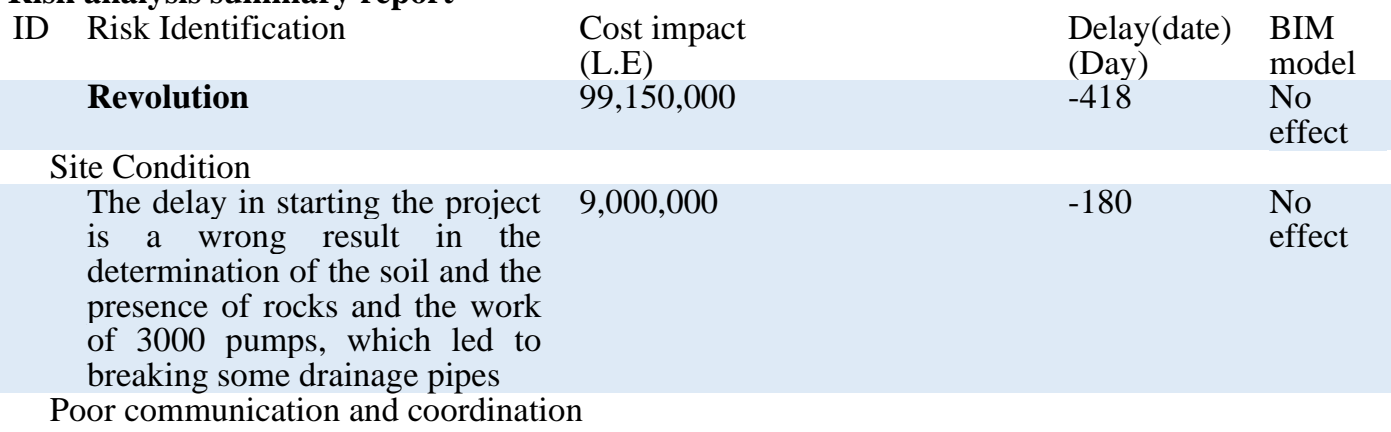




\begin{tabular}{|c|c|c|c|c|}
\hline 1 & $\begin{array}{l}\text { A clash between Air } \\
\text { conditioning and windows and } \\
\text { doors of the architect }\end{array}$ & $605,000(10 * 24,200+10 * 36,300)$ & -20 & $3 \mathrm{D}$ \\
\hline 2 & $\begin{array}{l}\text { A clash between drainage pipes } \\
\text { and beams }\end{array}$ & $968,000(20 * 48,400)$ & -20 & $3 \mathrm{D}$ \\
\hline 3 & Lack of shop drawings & $484,000(10 * 48,400)$ & -10 & $3 \mathrm{D}$ \\
\hline 4 & Lack in receiving BOQ & $387,200(8 * 48,400)$ & -8 & $3 \mathrm{D}$ \\
\hline \multicolumn{5}{|c|}{ Delay due to late in delivery } \\
\hline 5 & Delay in supplies & $3,000,000$ & 60 & $\begin{array}{l}\text { No } \\
\text { effect }\end{array}$ \\
\hline \multicolumn{5}{|c|}{ Changing orders } \\
\hline 6 & $\begin{array}{l}\text { Change the walls of the } \\
\text { radiology rooms from ordinary } \\
\text { walls to lead walls }\end{array}$ & $726,000(15 * 48,400)$ & -15 & 3D\&5D \\
\hline 7 & $\begin{array}{l}\text { The Ministry of Health during } \\
\text { the completion of the ground } \\
\text { floor said the list has changed } \\
\text { and must move outpatient clinics } \\
\text { from the ground floor to the first } \\
\text { floor }\end{array}$ & $532,400(11 * 48,400)$ & -11 & $3 \mathrm{D} \& 5 \mathrm{D}$ \\
\hline \multicolumn{5}{|c|}{ Delay due to errors } \\
\hline & Brickwork to roof level & $290,400(6 * 48,400)$ & -6 & 4D \\
\hline & Total (without BIM) & $118,000,000$ & -795 & \\
\hline & Total (with BIM) & $114,007,000$ & -705 & \\
\hline & BIM Saved & $3,993,000$ & 90 & \\
\hline
\end{tabular}

Table 2. Risk summary report

The difference between the traditional method and applied BIM technology achieved from the result of Implemented BIM in the case study

\begin{tabular}{|c|c|c|}
\hline & Traditional method & BIM \\
\hline \multirow[t]{2}{*}{ Programs } & AutoCAD 2D & Revit \\
\hline & Primavera & Naviswork \\
\hline Data & Not accurate & Extract more accurate data \\
\hline Drawings & Traditional drawings & $\begin{array}{l}\text { Enhancing the coordination } \\
\text { and integration between the } \\
\text { drawings }\end{array}$ \\
\hline Cost Estimate & Take long time & More accurate \\
\hline Stakeholders & Difficult to connect & $\begin{array}{l}\text { Enhancing the collaboration } \\
\text { between the stakeholders }\end{array}$ \\
\hline BOQ & $\begin{array}{l}\text { Take long time and not } \\
\text { accurate }\end{array}$ & Fast and more accurate \\
\hline Clashes & Not detected & detected \\
\hline Cost overrun & More cost & Save cost \\
\hline Time overrun & more time & Save time \\
\hline
\end{tabular}

Table 3.Comparison between traditional method and BIM 


\section{Discussion}

\subsection{The Questionnaire Results Discussions}

The questionnaire consisted of 2 parts (questions for engineers used BIM-questions for engineers didn't use BIM) and the most important result from it is as follow:

- Approximately $50 \%$ of the total respondents did not have a team management that faces the projects in their companies.

- Approximately $67 \%$ of the total respondents dealt with problems which face the project during the project periodically in their companies.

- Approximately $77 \%$ of the total respondents did not use BIM in their companies.

- Approximately $9 \%$ of the total respondents said that most important benefit of using BIM in their projects is cost-saving and quality control, $8 \%$ of the total respondents said that most important benefit of using BIM in their projects is quality control, saving time, saving money, and achieving safety (all of them), 6\% of the total respondents said that most important benefit of using BIM in their projects is quality control.

From analyzing the data, the following discussion is obtained on checking whether the results are expected or unexpected, comparing these results to the previous work

\subsection{The Case Study Results Discussions}

- The results of the case study discuss the difference between the traditional methods and applying Building Information modeling BIM at the construction projects in all stages. As shown in the table below. The spread of BIM in Egypt is still limited and has many restrictions. Some big companies only implemented BIM such as EHAF, Palm Hills and ECG. In the 3Dimensional model clash detection is the most benefit of used BIM that controlled cost and time. In the 4-Dimensional model the rework and any change in time schedule applied so easy to the model.

- Control the Poor communication and coordination

- Clashes between Sanitary and electrical in facility building at twelve positions, everyone takes one day to defect.

- Clash between Structure and MEP in facility building.

- Lack of shop drawings.

- Control the Delay due to design error.

- Wrong in calculating column initial duration.

- $\quad$ Lack of slabs due to the columns lack.

- Control changing material type.

- Change order from the traditional to FRP.

- Change interfaces from traditional to stone.

- Control the Rework due to errors during construction.

- Order to execute second-floor column at the same time the under a slab is demolition.

\section{Conclusion}

- It was clear from the case studies that any construction project faces many errors during the designing phase that may have an effect on the project time, cost and quality which could lead to inefficiency and disappointing results. However, the project. However, using some of the BIM features in project phases especially from the start of any project helps in avoiding these errors and leading to more efficient project.

- Based on the application of the 3D model, it is evident that it is effective to use a 3D model in all the project stages. In these case 
studies using the 3D model was very significant in solving the problems caused due to applying the traditional method and the focus on the clash zone which can be limited with using 3D model and build an effective connection with every section in the project( civil, architecture, mechanical, ...etc.).

- Based on the application of the 4D model, it is evident that it is effective to use a $4 \mathrm{D}$ model in both the design and the construction phases. The simulation of the 4D model makes every day in the project very clear and accurate.

- Based on the application of the 5D model, it is evident that it is effective to use a $5 \mathrm{D}$ model in both the design and the construction phases and also after project delivery. It is also proved that some of the BIM benefits in the first case study will positively affect project's overall cost and time.

- It is concluded from the case study that BIM is an integrated process that includes all implementation steps from the start to the delivery of any project. It is also useful in establishing a controlled system that provides follow-up on all steps of the project and help in achieving the owner's goals.

- With BIM we can successfully increase labor productivity, thereby lowering its net cost, changed or reduced the amount of materials used and wasted on a job site to lower their net cost.

- BIM has the potential to provide us with far more efficient operation, not only as part of design and construction but also in operations and maintenance. Accuracy is another main reason.

- After applying BIM in the project as case study, it is evident that the large and complex projects such as (large compoundshospitals) are more affected than small ones such as (mini compounds) as shown in figure 23.

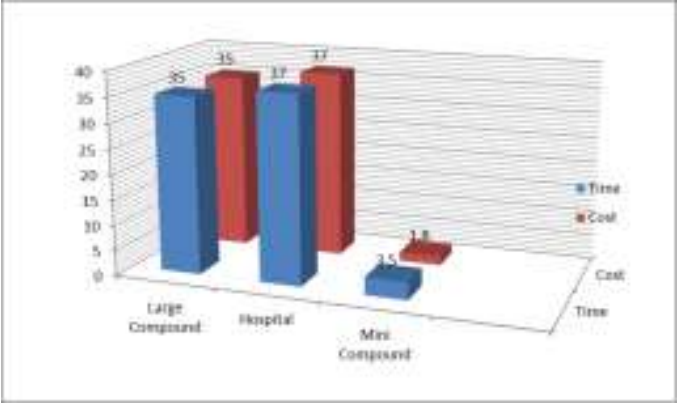

Fig.23. the Percentage of applying BIM technology on different construction projects

\section{Recommendations}

- Higher coordination between the departments of the project led to the discovery of problems before the start of implementation and resolved during the design phase and thus avoid the problem of non-compliance with the time schedule for the project and extending the period of the project more than once.

- Avoid problems resulting from the continuous modification of the project, which presents the project for an additional cost of extra time. Now the whole amendment is in record time and coordination between all parties to the project

- Continuous communication between the parties to the project. This technique made all the details of the project and clear by everyone.

- Great to take advantage of the technology BIM has to be applied properly between the parties involved in the project and take action to support that training, coordination and identification of tasks and setting standards are working out and follow-up.

- code provides the best way to practice, develop and organize information and help designers prepare the information before passing it to the implementation team 


\section{References}

1. Shan, Y. (2014). Integrated information modeling of construction project productivity (Doctoral dissertation, University of Colorado at Boulder).

2. Attallah, S. O. (2014). A life cycle analysis approach for the enhancement sustainability decision-making in the construction industry using agentbased modeling (Doctoral dissertation, Purdue University).

3. Atin, A. (2016). Project Risk Propagation Modeling Of Engineering, Procurement and Construction.

4. Perrenoud, A. (2014). Exploratory Study of Risk Maturity Impact on Construction Project Outcomes (Doctoral dissertation, Arizona State University).

5. Solnosky, R. L. (2013). Integrated Structural Process Model: An Inclusive Non-Material Specific Approach to Determining the Required Tasks and Information Exchanges for Structural Building Information Modeling.

6. Bu-Qammaz, A. S. (2015). Risk Management Model for International Public Construction Joint Venture Projects in Kuwait (Doctoral dissertation, The Ohio State University).233-238.

7. Ge, X. J., Livesey, P., Wang, J., Huang, S., He, X., \& Zhang, C. (2017). Deconstruction waste management through $3 \mathrm{~d}$ reconstruction and bim: a case study. Visualization in Engineering, 5(1), 13.

8. Hosney, R. M. (2016) Building Information Modeling (BIM) in the Egyptian Construction Industry (Master's thesis, Ain shams University).

9. Eastman, Chuck \& Teicholz, Paul M. (2008). BIM for the Construction Industry (BIM Handbook 2nd edition).

10. Duke, W. M. (2013). Building Information Modeling: How it can benefit Modern Construction Project in a university setting.
11. Hammad, D.B., Rishi, A.G. and Yahaya, M.B. (2012) Mitigating construction project risk using Building Information Modelling (BIM) In: Laryea, S., Agyepong, S.A., Leiringer, R. and Hughes, W. (Eds) Procs 4th West Africa Built Environment Research (WABER) Conference, 2426 July 2012, Abuja, Nigeria, 643-652.

12. Montaser, A. M. (2010). Value Engineering using Building Information Modeling (Master's thesis, Ain shams University).

13. Kia, Saeed (2013). Review of Building Information Modeling (BIM) Software Packages Based on Assets Management.

14. Hill, Mc. Graw (2013). National BIM Standard - United States.

15. MacLeamy, P. (2012). "Industrial strategy: government and industry in partnership: Building Information Modeling". United Kingdom: Department for Business Innovation \& Skills BIS, United Kingdom Government.

16. Won, J., Cheng, J. C., \& Lee, G. (2016). Quantification of construction waste prevented by BIM-based design validation: Case studies in South Korea. Waste Management, 49, 170180.

17. Bhamre, G. , Patil, A. \& Pataskar, S. (2017). Cost and Time Optimization for Construction of Residential Building by Clash detection in Building Information Model(BIM), International Research Journal of Engineering and Technology (IRJET).

18. Cribbs, J. (2016). Workflow Management Using Building Information Modeling (BIM) for Prefabrication in a Construction Retrofit Environment.

19. Bueno, C., \& Fabricio, M. M. (2016). Application of building information modelling (BIM) to perform life cycle 
assessment of buildings. Revista Pósv, 23(40), 96-121.

20. Bohórquez-Castellanos, J. J., PorrasDíaz, H., Sánchez-Rivera, O. G., \& Mariño-Espinel, M. C. (2018). Planificación de recursos humanos a partir de la simulación del proceso constructivo en modelos BIM 5D. Entramado, 14(1), 252-267.

21. O'Keeffe, S. E. (2013). Synergy of the developed 6D BIM framework and conception of the $\mathrm{nD}$ BIM framework and $\mathrm{nD}$ BIM process ontology (Doctoral dissertation, The University of Southern Mississippi).

22. Shrestha, P. P., \& Mani, N. (2013). Impact of design cost on project performance of design-bid-build road projects. Journal of Management in Engineering, 30(3), 04014007.

\author{
Appendix A \\ Research Title: \\ Building Information Modeling BIM as a \\ Development tool for the Management of \\ Construction Projects \\ The Purpose of This Survey:
}

The purpose of this short survey is to begin to gather information about the effect of implementing Building Information Modeling BIM on the mitigation of construction project management during all phases of the project in Egypt.

The results of this survey will be summarized in a report that will be shared with all respondents in appreciation for their participation.

1. Does your company currently use BIM, or is it intending to use BIM in the near future?

- Yes

- No

Will be implemented soon

2. In what way do you think the implementation of BIM will affect the following key tasks performed?

a. Preparation of tender and contract documents

(Low - Medium - High)

b. Cost analysis and lifecycle costing

(Low - Medium - High)

c. Identifying and developing responses to risks (Low - Medium - High)

d. Analyzing proposed outcomes

(Low - Medium - High)

e. Valuing completed work and arranging payments (Low - Medium - High)

f. Clash detection during a design phase (Low - Medium - High)

3. How many projects did you implement BIM?

- From(1 to 5)

- From(6 to 10) 


\section{"نمذجة معلومات البناء BIM كأداة تطوير في إدارة مثاريع البناء"}

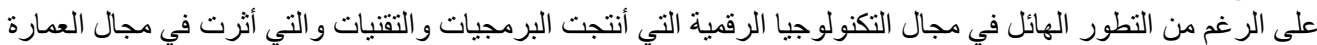

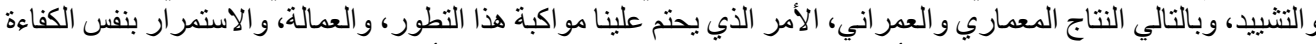

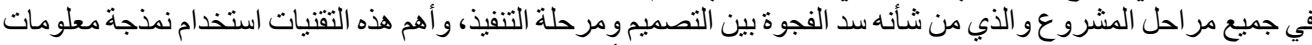

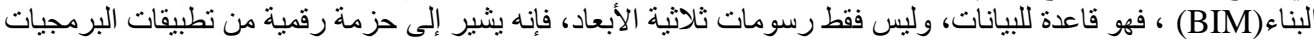

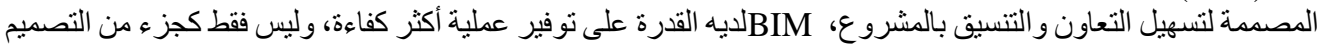

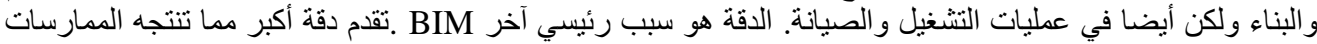

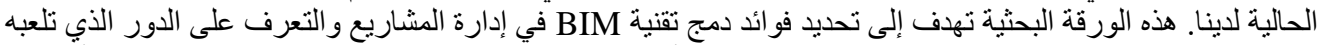

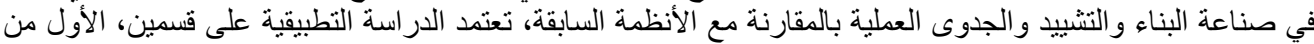

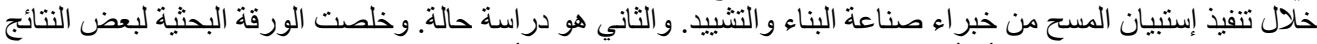

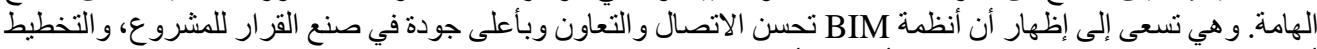

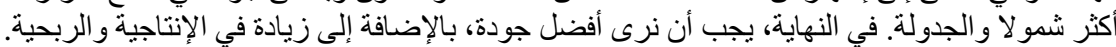

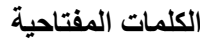
نمذجة معلومات البناء، الأدارة ، مشاريع التشييد. 